\title{
A república mundial das roupas e a modernidade de Machado de Assis
}

\section{World republic of clothes and Machado de Assis's modernity}

[resumo] Neste artigo, parte-se da noção de República Mundial das Letras, cunhada pelo francês Valery Larbaud, para refletir sobre as relações existentes entre a obra de Machado de Assis e outros autores, como Flaubert e Baudelaire, e as roupas. 0 discurso indumentário presente nos autores citados permite perceber outros pontos de contato interliterário que não têm sido abordados sistematicamente pela crítica. A inserção de Machado de Assis nesta discussão coloca-o, uma vez mais, no centro do discurso literário de sua época.

[abstract] This paper starts with the notion of World Republic of Letters, created by French translator and author Valery Larbaud, to discuss relationships between the work of Machado de Assis and other authors, such as Flaubert and Baudelaire, and clothes. Dressing discourse, present among the related authors, makes one realize other inter-literary spots of contact that haven't been analyzed systematically by critic. Machado de Assis's entrance in this discussion places him, once more, in the centre of the literary discourse of his time.

[key words] Machado de Assis; literary interzone; clothes. 


\section{Machado de Assis e as identidades brasileiras}

(...) refiro-me ao gesto correto e perfilado com que usas expender francamente as tuas simpatias ou antipatias acerca do corte de um colete, das dimensões de um chapéu, do ranger ou calar das botas novas. Eis aí um sintoma eloquente, eis aí uma esperança. (Machado de Assis, Teoria do Medalhão)

Há mais de cinquenta anos, Antônio Cândido de Mello e Souza (1959) já afirmava que estudar literatura brasileira é estudar literatura comparada, pois, mesmo na negação das raízes europeias, essa literatura buscava identificar-se através das diferenças, e não das semelhanças, ora com sua língua mãe, o português de Portugal, ora com a língua literária do século XIX, o francês.

Se a literatura brasileira se constituiu na identificação com uma literatura europeia irradiada do centro intelectual do século XIX e, ao mesmo tempo, através de sua ligação inexorável com o português de Portugal, não há como negar seu pertencimento a uma interzona literária.

0 mosaico de culturas de que é feita a literatura brasileira já a torna um discurso no entre-lugar, uma terceira margem do rio, como diria João Guimarães Rosa (1988) no conto homônimo. Portanto, a caracterização híbrida dessa literatura, seja pela língua que lhe dá origem, seja pelas leituras de textos e de mundos das quais ela se origina, é marco fundador nessa cultura híbrida e mestiça, ainda perpassada pelos valores indígenas, africanos e dos imigrantes europeus e asiáticos que ao Brasil acorreram posteriormente.

Se hoje a discussão a respeito de uma identidade da literatura brasileira já não é mais tão angustiante, é porque aceitamos nossas influências, e, como sentenciou Oswald de Andrade no Manifesto antropofágico, a cultura brasileira é fruto de uma digestão de todas as culturas das quais se alimenta. Ou seja: o escritor e o artista brasileiro jamais devolvem ao mundo algo "puro", pois o que retorna foi digerido e amalgamado a um caldo cultural rico no qual convivem as culturas que compõem esse mosaico.

Joaquim Maria Machado de Assis conseguiu a façanha de representar simultaneamente o escritor brasileiro e aquele que pertence a uma literatura do mundo. Mesmo que quisesse reescrever as sagas de nossos nativos, como fez José de Alencar em 0 Guaranie em Iracema, o que subsiste em Machado de Assis diz respeito a uma visão uma vez eurocêntrica, mas que, no pós-romantismo, já encontra uma língua toda sua. Apesar da dissonância de temas, sabe-se hoje que no Brasil só foi possível a existência de um Machado de Assis universal porque houve um José de Alencar regional e provinciano, em busca de uma marca literária própria, sempre centrada no problema fundador: o de uma identidade brasileira.

Ultrapassando um destino manifesto de escrever o exótico que se espera dos escritores e dos artistas brasileiros de maneira geral - ainda mais quando viveram e escreveram no século XIX -, Machado de Assis (1839-1908) - "um mestre na periferia do capitalismo", segundo Roberto Schwarz (2006) - é o escritor brasileiro que finalmente consegue escrever nessa língua que não é nem a busca da "identidade perdida" dos brasileiros - seu objetivo não é esse, mas dotar o brasileiro de uma voz literária própria - nem o suposto reencontro com suas influências europeias.

Irreverente leitor dos clássicos, tradutor de Edgar Allan Poe, ainda que identificando seus escritos com Laurence Sterne, Xavier de Maistre e Stendhal, em Memórias póstumas de Brás Cubas e em Dom Casmurro, por exemplo, é dos seus arredores que Machado de Assis nos fala. Mas esses arredores são muito mais amplos: eles não apenas dizem de indivíduos que convivem nos bairros de um Rio de Janeiro que passa da transição do Império à República, de cidadãos que discutem a política da época, a questão da nacionalidade, dos costumes de sua sociedade, que ironizam a moral contemporânea a si.

Fundamentalmente, as personagens de um Machado contaminado por suas múltiplas leituras reconstroem o percurso em um espaço intelectual da época: o do próprio Machado de Assis, mestiço brasileiro, filho de pai mulato e mãe portuguesa, que, egresso das classes subalternas, será alçado à condição de maior escritor brasileiro, de fundador de uma identidade literária que ultrapassa seu próprio tempo e seu espaço de pertencimento inicial. 
Machado é, ainda, no Brasil, o responsável por uma ideia de Modernidade: a partir de seu romance Memórias póstumas de Brás Cubas, de 1880, será possível perceber a inserção de um novo estilo literário que rompe com o que vinha sendo feito antes, mesmo pelo próprio Machado de Assis. Esse novo estilo traz, por exemplo, o "defunto autor", um homem que, depois de morto, resolve escrever suas memórias, sem a preocupação de se expor publicamente: a morte lhe dá a possibilidade da honestidade total. 0 espaço da página também será utilizado de outra forma, muitas vezes com espaços em branco ou reticências, como Laurence Sterne, em quem o próprio Machado diz ter se inspirado.

Na sua inconformidade literária, Machado acaba por criar, além de seu escritório reconstruído na Academia Brasileira de Letras, um verdadeiro "museu portátil", a la Duchamp. Cada obra de Machado permite penetrar num horizonte a um tempo representativo do nacional - brasileiro - e do ocidental - europeu. Como um escritor brasileiro, teoricamente provinciano, consegue entrar na seara da Modernidade?

João Cezar de Castro Rocha (2006) nos acena com essa discussão quando cita John Gledson, que, por sua vez, reflete sobre a teoria de Roberto Schwarz a respeito de Machado.

A grande realização de um mestre, penso, é explicar um paradoxo aparente: como é que um autor tão enraizado em sua própria época, escrevendo num contexto escravocrata, também é, de tantas maneiras, tão avançado? A grande percepção de Schwarz (...) é que a modernidade surge paradoxalmente, em considerável extensão, de dentro do retrógrado, e não meramente acontece contrário a ele. (ROCHA, 2006, p. XXXI, tradução nossa)

Ou seja, as Modernidades são múltiplas e simultâneas. Machado, à sua moda, inspirou e construiu uma Modernidade brasileira, com todos os paradoxos advindos de nossa realidade singular. Ao mesmo tempo, Rocha cita, na questão referente às ideias de centro e periferia, o trabalho de Carlo Ginzburg e Enrico Castelnuovo em uma discussão dos anos 1970 sobre a história da arte italiana:

Se o centro é, por definição, a localização da criação artística, e a periferia simplesmente significa distância do centro, então não se pode não considerar a periferia sinônimo de atraso artístico. É claro, esse é um esquema tautológico, que elimina a dificuldade, embora pretenda resolvê-la. (...) Vista através de uma perspectiva polivalente, a relação entre 0 centro e a periferia revela-se muito diferente de uma imagem pacífica (...). Não se trata de difusão, mas de conflito, que pode ser observado mesmo em situações nas quais a periferia parecer limitar-se a seguir fielmente as ordens do centro. (ROCHA, 2006, p. XXII-XXIII, tradução nossa)

Se o centro não é, nessa visada, o "lugar" de uma superioridade artística ou intelectual, assim como a periferia não é, igualmente, o lugar de uma suposta inferioridade ou de um atraso, no mesmo sentido, não é que haja uma inversão de valores, mas simplesmente uma nova convivência de espaços com características e propostas diferentes: uma nova "interzona" mental, uma "República Mundial das Letras" sem lugares inferiores e superiores no que concerne aos colonizados e colonizadores, como quer Pascale Casanova (2002), relendo Valery Larbaud, d'après Goethe com sua Weltliteratur. Aliás, é a própria colonização, diga-se de passagem, que acaba por propiciar esse encontro tão produtivo. Não se trata, portanto, de demonizar a colonização, mesmo porque os impérios são também de papel. 
Machado de Assis e os "museus portáteis": as roupas como textos revestidos de significados da Modernidade

Há, em nosso entendimento, outra maneira de inserir Machado de Assis e seus "museus portáteis" em uma discussão acerca da Modernidade e de sua "interzona" literária: o papel das roupas em seus escritos, e como as roupas falam como textos que são, de suas personagens e do mundo que habitam, assim como na obra de autores contemporâneos a ele ou pouco anteriores, e por ele lidos, digeridos e transcriados. A roupa, nesses autores, passados já mais de um século e meio de escritura, funciona mesmo como memória de um tempo e de uma escrita literária. Se Antônio Olinto, na introdução de 0 espírito das roupas, nos fala da relação entre vestes reais e imagéticas propostas por Barthes, assim como da reflexão de Gilda de Mello e Souza (2009) acerca da veste-escrita, creio que podemos pensar numa escrita das vestes que nos proporciona Machado. De fato, de acordo com a ideia do zeitgeist que impregna a análise de Gilda, bem poderiamos pensar em uma escrita das vestes e do tempo.

Assim, a roupa e a moda, objetos de teorização sociológica em fins do século XIX - por Georg Simmel, Thorstein Veblen e Gabriel de Tarde -, previam um uso social poderoso naquela sociedade altamente cindida pelas classes sociais. A roupa, já o sabemos, denunciava, além do gênero, uma classe, uma função, uma origem e mesmo um pertencimento político-ideológico. A roupa era a materialização da distinção social.

A socióloga norte-americana Diana Crane desenvolveu um longo estudo sobre a questão da moda no século XIX perante as transformações sociais e de gênero. Em sua pesquisa, ela pôde perceber quão decisivo foi o papel das roupas nesse século para a construção da sociedade tal como a conhecemos.

0 vestuário, sendo uma das formas mais visíveis de consumo, desempenha um papel da maior importância na construção social da identidade. A escolha do vestuário propicia um excelente campo para estudar como as pessoas interpretam determinada forma de cultura para seu próprio uso, forma essa que inclui normas rigorosas sobre a aparência que se considera apropriada num determinado período (que é conhecido como moda), bem como uma variedade de alternativas extraordinariamente ricas. Sendo uma das mais evidentes marcas de status social e gênero - útil, portanto, para manter ou subverter fronteiras simbólicas -, o vestuário constitui uma indicação de como as pessoas, em diferentes épocas, vêem sua posição nas estruturas sociais e negociam as fronteiras de status. (CRANE, 2006, p. 21)

Longe de ser mero adorno, a roupa denuncia uma reflexão simbólica no âmbito do texto. Escritores e ensaístas como Michel de Montaigne, desde o século XVI, refletiram sobre o papel das roupas e seu uso social. 0 século XIX é o que mais concentra autores comprometidos com a Moda. 0 fato de autores como Baudelaire (2010) refletirem sobre a indissociação da Moda e da mulher, por exemplo, não é casual. Assim como os precursores da Modernidade, a Moda também se funda no novo como valor em si. Além disso, vale lembrar que o advento da Moda corresponde ao momento do desenvolvimento da ideia de indivíduo, servindo a roupa, já nesse momento, à construção de uma identidade social.

A respeito disso, pontua Regina A. Root $(2002$, p. 89):

As roupas têm funções tão visiveis que se tornam facilmente descartáveis, trivializadas ou totalmente esquecidas. Mas o mesmo casaco que protege também distingue a classe social de alguém, assim como suas afinidades políticas. (...) no século dezenove, vários escritores influentes usaram a trivialidade aparente da moda para importar ideais revolucionários, usando o que pareciam ser descrições inócuas de roupas e tendências de moda. Indo além do relato das inovações na indústria da moda e no detalhamento de novas peças de roupas, esses escritos imbuíram tudo, das pantalonas às anáguas, de um significado radical no espetáculo de uma esfera pública emergente. 
A fundação de um sistema da Moda, em finais da Idade Média, corresponde a uma ideia de sazonalidade e de um ciclo da Moda, em que a Corte define um padrão a ser copiado posteriormente por uma burguesia nascente. Dessa forma, quando a Moda chegasse à burguesia através da "cópia", seria já substituída por novos modelos, tecidos, cortes, pela nobreza.

É claro que esse ciclo, com o tempo, vai sendo comprimido e, a partir de 1860, mais ou menos, com o advento da alta-costura por Worth, finalmente atinge a ideia de coleções por estação, como ocorre até hoje. Portanto, a institucionalização da Moda na cultura francesa e europeia, de maneira geral, está no cerne da Modernidade.

\section{As teorias da moda e a literatura}

Embora desde o século XIX estudos teorizando sobre a Moda tenham sido produzidos por sociólogos, como o alemão Georg Simmel - A moda, 1894 -, 0 estadunidense de ascendência norueguesa Thorstein Veblen, com a sua Teoria das classes ociosas, de 1895, e o francês Gabriel de Tarde - As leis da imitação, 1894 -, esse campo de estudos continuou relegado a um plano infinitamente secundário até bem pouco tempo atrás. Mesmo Thomas Carlyle, com seu Sartor resartus: the tailor re-tailored, de 1833-34, debruçou-se de forma mais ou menos filosófica e até satírica sobre o tema.

Autores franceses do século XIX como Honoré de Balzac, Gustave Flaubert, Charles Baudelaire e Stéphane Mallarmé priorizaram, em suas escritas literárias e críticas, a roupa como um fator essencial de compreensão da sociedade em que viviam. Os dois últimos chegaram mesmo a estabelecer estudos críticos sobre o papel da Moda em seu tempo e das modas como novidade e como fatores fundamentais ao advento da chamada Modernidade, perpassada em amplo espectro pela criação literária.

Baudelaire (2010, p. 69) chega a sentenciar que

A mulher é, sem dúvida, uma luz, um olhar, um convite à felicidade. Uma palavra, às vezes, mas é principalmente uma harmonia geral, não somente em seu andar e no movimento de seus membros, mas também nas musselines, filós, nas vastas e cambiantes nuvens de tecido com que se envolve, e que são como pedestal de sua divindade, no metal e mineral que lhe serpenteiam os braços, o colo, que juntam suas fagulhas ao fogo de seu olhar, ou que sussurram docemente a seus ouvidos. Que poeta ousaria, na pintura do prazer causado pela aparição de uma beleza, separar a mulher de sua roupa?

Para melhor aprofundar a questão, tais autores escreveram sobre o papel das roupas, tendo Mallarmé criado uma "gazette" intitulada La Dernière Mode, em circulação entre setembro e dezembro de 1874. Se esses autores estabeleceram em sua reflexão, ainda no século XIX, o papel que as roupas conferiam às personas que as vestiam, é porque perceberam as possibilidades de análise que nossa superfície mais palpável tornava visivel de uma relação com o mundo exterior.

De fato, principalmente no século XIX, o que se cobria e o que se descobria do corpo humano era identificador de uma dada ordem social e do pertencimento a uma classe ou mesmo a uma visão política. No caso feminino, por exemplo, o uso dos espartilhos e das anquinhas tornava as mulheres das classes ociosas ainda mais apáticas, na medida em que impossibilitavam quase totalmente seus movimentos corporais.No caso masculino, a institucionalização de um "uniforme" de trabalho, o terno, constitui um novo dado concernente ao mundo industrialista, sem espaço para babados e cores pastel anteriormente em voga na indumentária do homem. 0 papel da ornamentação, a partir daí, foi conferido especialmente, na sociedade ocidental, às vestes femininas, que, além do mais, auxiliavam na exposição do status social do marido. As vestes femininas são, para Emma Bovary, por exemplo, parte considerável da construção de sua 
personagem, denotando estados de espírito e sendo até mesmo, muitas vezes, motivo de sua ruína. Não por acaso, Flaubert (2007) apostou na roupa como uma maneira de melhor apresentar a sociedade que criticava e na qual sua heroína - ainda que com uma postura antitética - estava imersa. Emma, uma consumista desenfreada, muitas vezes aparece em função do traje que usa ou se significa em função dele.

Honoré de Balzac (1979), em As ilusões perdidas, dá uma importância significativa às vestes de Lucien de Rubempré. 0 crescimento da personagem, aliás, dentro de sua escala social, se dá, originalmente, em um primeiro momento, em função das "melhores" roupas com as quais se apresentará, sendo assim mais bem recebido pela sociedade da qual queria fazer parte.

Vê-se, então, que é na literatura, inicialmente, que haverá uma reflexão sistematizada sobre o caráter das roupas na sociedade moderna. Se os textos historiográficos mais percebiam apenas a classificação social através das roupas, é nos textos literários que aparece uma análise de perfis individuais e sociais em função do vestuário.

Além disso, se a roupa pode ser analisada como é atualmente - como um discurso, uma narrativa -, é porque se constitui em fonte ela mesma para análise sociocultural de um momento dado, como uma espécie de "museu portátil".

0 primeiro dandy, George (Beau) Brummell, além de ter sido um verdadeiro revolucionário na indumentária masculina do século XIX, foi ainda uma inspiração para autores como o próprio Baudelaire e, mais tarde, Oscar Wilde, este um defensor da cultura das aparências como a mais verdadeira possível dentro da sociedade inglesa. Com o estilo mais despojado que propôs Brummell, deu ao homem inglês, e posteriormente ao homem ocidental, o aspecto mais próximo do discurso indumentário que ele detém até hoje, com a utilização da sobriedade de uma maneira inédita que homogeneizou a parcela masculina da sociedade inglesa da metade final do século XIX. Barbey D'Aurevilly (2009) escreveu contemporaneamente sobre o tema ao identificar Brummell como o modelo para o homem de sua época: sóbrio e determinado a fazer de sua aparência uma forma de vida.

A moda deixava, pois, de ser indumentária apenas para se converter em estilo de vida, com uma simbologia própria, o que seria reiterado mais tarde pelo psicólogo inglês John Carl Flügel (1966), em seu tratado sobre aspectos afetivos e sociais das roupas, com trabalhos publicados já nos anos 1920, nos quais mostrava serem as roupas, também, além de protetoras, adornadoras e pudicícias, comunicantes entre homens e mulheres e a sociedade em geral.

A escritora inglesa Virginia Woolf, na mesma época, versa sobre o papel das roupas em sua obra, principalmente no romance Orlando, de 1928, e em textos curtos, como o conto $O$ vestido novo, do mesmo ano. Mesmo no texto, já convertido em clássico dos estudos feministas, Um teto todo seu (1928), a autora reflete sobre a diferença da indumentária na construção de identidades mais ou menos livres.

\section{A modernidade de Machado de Assis, a República Mundial das Letras e a moda}

Se Deus mora nos detalhes, como quer Aby Warburg, a prosa de Joaquim Maria Machado de Assis é uma obra-prima da costura de detalhes mínimos que fazem toda a diferença. Preso ao detalhe, Machado modelou com maestria a principal obra poética brasileira. Fundador e primeiro presidente da Academia Brasileira de Letras, 0 "Bruxo do Cosme Velho", como era chamado, rearticulou o romance brasileiro também nisso. Entre o Romantismo e a Modernidade, as múltiplas faces de Machado tornaram-no referência na construção de uma identidade da literatura brasileira.

Durante muito tempo, Machado foi analisado como o carioca cortesão que era; passado um século de sua morte, o horizonte de seu pertencimento não cessa de expandir-se. De escritor provinciano, passou a ser visto pela crítica internacional como escritor universal - segundo o americano Harold Bloom (2001), Machado seria o maior escritor negro de todos os tempos, enquanto Salman Rushdie e Woody Allen veem nele um grande escritor.

A prosa de Machado, que vai conquistando o mundo, está longe de dizer respeito apenas à realidade circunscrita às paisagens do Rio de Janeiro, pois esse é um autor que, segundo Rocha, 
(...) experimentou com coragem vários estilos literários, apropriou-se livremente da tradição literária, desenvolveu um rapport irreverente com o leitor através de uma série de experimentos com a voz narrado$\mathrm{ra}$, atribuiu ao ato de ler um papel central no ato de escrever, e brincou com o processo de reescrever o texto conforme o texto está sendo escrito com a atitude de comentar ironicamente sobre o processo de composição. (ROCHA, 2006, p. XXI, tradução nossa)

Ou seja, "carioca da gema", Machado leu a literatura europeia dos séculos XVIII e XIX com voracidade e nela fincou suas raízes. 0 território mental de Machado é o Rio de Janeiro apenas superficialmente: os estados de espirito e as discussões por ele propostas pertencem ao terreno do universal. Ao enfrentar os problemas poéticos de ordem geral, como a voz narrativa, a leitura como centro da escrita e a leitura como processo de reescrita, Machado deixa de estar vinculado especificamente à literatura brasileira, mas dialoga com a República Mundial das Letras, como um precursor de vários outros escritores, entre eles, o próprio Borges. Nesse momento, Machado torna-se central, sem nunca deixar de ser periférico. Está no entre-lugar. Escreve da sua interzona literária, a um tempo periférica, atrasada e antiga, mas também à frente de seu tempo, irreverente, iconoclasta, vanguardista, centrada no leitor como produtor de nexos textuais, como fariam seu sucessores.

E se podemos encontrar as raízes da obra machadiana já em Shakespeare, com um Othello ressemantizado em Dom Casmurro, será em Tristram Shandy, de Sterne, que ele se inspirará para marcar a passagem de estilos literários na história literária brasileira, com Memórias póstumas de Brás Cubas.

Entretanto, é na obra da descrição dos detalhes do cotidiano e da alma de autores como Balzac e Eça de Queirós - este também um "quase-periférico", pois pertencente a um pequeno país europeu, distante do centro intelectual, também leitor da dita "alta cultura" - que Machado encontrará os grandes intertextos para a Modernidade de sua forma livre ainda no século XIX. Com essa inovação - a forma livre -, Machado de Assis transforma o suposto atraso em Modernidade. Segundo Carlos Fuentes (citado por ROCHA, 2006, p. XXVII), é na angústia de provar uma independência literária que Machado de Assis agrega toda a sua cultura, todas as tradições - inclusive as literárias -, no desejo de criar uma síntese, um primeiro Aleph, como queria Borges. Mais uma vez, o que poderia ser demérito se transforma em projeto crítico ao agregar mundos aparentemente antípodas e anacrônicos.

0 papel das vestes como discurso não verbal na obra dos autores citados é significativo e propõe que, além das letras, as roupas também se constituem em uma ferramenta fundamental para a construção de uma Modernidade, se não artística, cultural.

Na relação com a literatura, a Moda recebe um papel decisivo: o de fixar, através de sua descrição, um momento da história. Indo além: a Moda descreve estados de espírito. A própria Virginia Woolf, em 1925, chega a escrever no seu diário que gostaria de entender melhor o que ela chama de uma "consciência do vestir", bem de acordo com sua estética textual, em que existe um fluxo de pensamentos e emoções. Não por acaso, o título da obra de Gilda de Mello e Souza é 0 espírito das roupas.

As metáforas das quais se utiliza Machado quando descreve roupas, adornos e cortes de cabelo ou de barba e bigode se assemelham à maneira de que se utilizam os autores europeus anteriormente citados. Essas descrições, longe de apenas caracterizar fisicamente as personagens, externam estados de espírito, convicções políticas ou religiosas e, claro, pertenças sociais. Mais que isso: atestam uma preocupação filosófica com a questão indumentária.

No conto Capítulo dos chapéus, Conrado Seabra, o marido criticado pelo uso anacrônico de um chapéu baixo, defende que essa é uma questão metafísica e que 0 chapéu como extensão corporal do homem não pode ser simplesmente trocado sem que haja um câmbio correspondente de pensamentos e atitudes. Nesse mesmo texto, encontramos uma discussão machadiana absolutamente de acordo com a discussão 
atual mesmo em torno da moda. 0 sogro de Conrado queixa-se à filha, Mariana, do chapéu do genro. Machado apresenta o passado, a tradição, sob a forma do sogro:

\begin{abstract}
Era um bom velho, magro, pausado, ex-funcionário público, ralado de saudades do tempo em que os empregados iam de casaca para suas repartições. Casaca era o que ele, ainda agora, levava aos enterros, não pela razão que o leitor suspeita, a solenidade da morte ou a gravidade da despedida última, mas por esta menos filosófica, por ser um costume antigo. (ASSIS, 1997, p. 210)
\end{abstract}

Mais adiante, Conrado defende-se da acusação de portar mal um chapéu quiçá despretensioso demais, ao esclarecer que 0 adorno representa sua relação com o mundo que o cerca, que coroa e corrobora seus pensamentos. Se o sogro é apresentado como alguém que vê nas roupas a honra aos costumes do passado, a relação com a tradição do uso e do costume é o genro, mais jovem, sujeito ativo do presente, aquele que defende a roupa como fator significante, como objeto que porta uma reflexão acerca do mundo. Voltando às reflexões baudelairianas, podemos referi-lo a esse respeito:

Um dia desses, talvez, aparecerá uma peça, num teatro qualquer, na qual veremos a ressurreição dessas roupas sob as quais nossos pais se consideravam tão encantadores quanto nós mesmos em nossas pobres vestes (as quais também têm sua graça, é verdade, mas de uma natureza sobretudo moral e espiritual), e se forem envergadas e animadas por atrizes e atores inteligentes, nós nos admiraremos de que tenha sido possivel terem tão tolamente se rido delas. 0 passado, sem deixar de conservar o atrativo do fantasma, retomará a luz e o movimento da vida e se tornará presente. (BAUDELAIRE, 2010, p. 14)

No caso de Machado, especificamente, as roupas serão acessório fundamental para que ele possa usar de um de seus traços mais característicos: a ironia. As roupas expõem, com sarcasmo, o que homens e mulheres são ou deixam de ser, o que os inspira, o que confessam ou o que seduzem. Ou seja, muitas vezes, é por meio das roupas que Machado consegue criar o cenário necessário ao que querem dizer corporalmente os seres que habitam seus textos.

Um dos exemplos mais apurados está em Memórias póstumas de Brás Cubas, quando o narrador resolve questionar o tamanho da barretina - chapéu militar - da guarda nacional ao Ministro e sua relação com a saúde e a autoestima dos soldados e, portanto, da pátria:

Três dias depois, discutindo-se o orçamento da justiça, aproveitei o ensejo para perguntar modestamente ao ministro se não julgava útil diminuir a barretina da guarda nacional. Não tinha vasto alcance o objeto da pergunta; mas, ainda assim, demonstrei que eu não era indigno das cogitações de um homem de Estado; e citei Filopêmen, que ordenou a substituição dos broquéis de suas tropas, que eram pequenos, por outros maiores, e bem assim as lanças, que eram demasiado leves; fato que a história não achou que desmentisse a gravidade de suas páginas. 0 tamanho das nossas barretinas estava pedindo um corte profundo, não só por serem deselegantes, mas também por serem anti-higiênicas. Nas paradas, ao sol, o excesso de calor produzido por elas podia se fatal. Sendo certo um dos preceitos de Hipócrates era trazer a cabeça fresca, parecia cruel obrigar um cidadão, por simples consideração de uniforme, a arriscar a saúde e a vida, e conseqüentemente o futuro da família. A câmara e o governo deviam lembrar-se de que a guarda nacional era o anteparo da liberdade e da independência, e que o cidadão, chamado a um serviço gratuito, freqüente e penoso, tinha direito a que se lhe diminuisse o ônus, decretando um uniforme leve e maneiro. Acrescia que a barretina, por seu peso, abatia a cabeça dos cidadãos, e a pátria precisava de soldados cuja fronte pudesse levantar-se altiva e serena diante do poder; concluí com esta idéia. (ASSIS, 1978, p. 186) 
Ao fazer uso desse tipo de análise "indumentária" em seus textos, Machado propicia que se leia a ironia que ele reserva à classe política brasileira e de como no final do seu século XIX são criados assuntos de Estado dessa envergadura. Assim como remete ao plano político esse tipo de análise, no plano cotidiano e social também a fará; em Dom Casmurro, por exemplo, quando cita a escumilha de Capitu, que não revela e tampouco esconde os ombros, mostrando, através das roupas, como essa personagem é paradoxal em todos os seus aspectos: Capitu é aquela que, com seu "olhar de ressaca", jamais é completamente apreendida, ela sempre parece ter uma posição ambígua.

Capitu, como objeto da dúvida que consome Bentinho, só poderia ser descrita em termos indumentários dessa forma: como alguém que nunca revela ou esconde completamente, alguém que deixa sempre a dúvida a respeito do que faz e aparenta ser - na visão do narrador-personagem, claro está. Dessa forma, a ambiguidade, que é a principal forma como será apresentada a ironia de Machado de Assis, tem na roupa uma de suas peças-chave.

Como podemos ver, o discurso proposto pelas roupas proporciona o entendimento das sociedades brasileira e francesa do século XIX de uma maneira muito particular. Assim como são lidos pelos autores, a roupa também traduz uma visão particular de mundo, e, assim como os textos são relidos, transcriados e modelados, as roupas também o são, assumindo o papel que o autor, como costureiro ou alfaiate que é, propõe. Dessa forma, o próprio autor se modela ao articular seu pertencimento literário a um espaço muito além da sua origem e de seu suposto destino.

No caso de Machado de Assis, ocorreu uma superação múltipla ao tornar-se precursor e sucessor em uma nova ordem literária, ao inserir-se em uma República Mundial das Letras e a uma Interzona Literária, passando, em nossa análise projetual, pela esfera do "vestir" textos, ideias, personagens com sua linguagem única, construída na "periferia", mas com um olhar que, vindo de suas leituras do "centro", se remodela criando uma nova língua literária que iria se tornar memória do pensamento nacional.

Essas são algumas das questões sobre as quais se pode refletir, partindo dos textos de Machado de Assis, seguindo uma parceria com os "republicanos das letras", Gustave Flaubert e Charles Baudelaire, em que o aspecto indumentário é privilegiado de forma a perceber uma nova relação da personagem no texto que configura uma linguagem inscrita a um tempo na Modernidade e na República Mundial das Letras, de forma a configurar uma interzona literária que passa por um texto não verbal: o da Moda.

Esta visada, então, propõe estabelecer uma interzona que diz respeito não apenas aos textos dos autores aqui focalizados, mas também o seu pertencimento em um sistema indumentário comum, no qual se leem não apenas uma ordem literária então vigente, mas também uma narrativa simbólica das vestes, através das quais, mais uma vez, encontramos uma República Mundial das Letras - e das Roupas, através desses diálogos entre-textos. 
artigo ] JOANA BOSAK

\section{REFERÊNCIAS}

ASSIS, Joaquim Maria Machado de. Memórias póstumas de Brás Cubas/Dom Casmurro. São Paulo: Abril Cultural, 1978.

Os melhores contos. Seleção de Domício Proença Filho. São Paulo: Global, 1997.

BALZAC, Honoré de. As ilusões perdidas. São Paulo: Abril Cultural, 1979.

BAUDELAIRE, Charles. 0 pintor da vida moderna. Belo Horizonte: Autêntica, 2010.

BLO0M, Harold. 0 cânone ocidental. Rio de Janeiro: Objetiva, 2001.

CASANOVA, Pascale. A república mundial das letras. São Paulo: Estação Liberdade, 2002.

CRANE, Diana. A moda e seu papel social: classe, gênero e identidade das roupas. São Paulo: Senac, 2006.

D'AUREVILLY, Jules Barbey. 0 dandismo e George Brummell. In: BALZAC, Honoré de; BAUDELAIRE, Charles; D'AUREVILLY, Jules Barbey. Manual do dândi: a vida com estilo. Belo Horizonte: Autêntica, 2009

FLAUBERT, Gustave. Madame Bovary. São Paulo: Nova Alexandria, 2007.

FLÜGEL, John Carl. A psicologia das roupas. São Paulo: Mestre Jou, 1966

GUIMARÃES ROSA, João. A terceira margem do rio. In Primeiras histórias. Rio de Janeiro: Nova Fronteira, 1988.

ROCHA, João Cezar de Castro (Org.). Author as plagiarist: the case of Machado de Assis. Dartmouth: UMass, 2006.

R00T, Regina A. Modelando a nação: escritos de moda na Argentina do século dezenove. Fashion Theory: a revista da moda, corpo e cultura. São Paulo: Anhembi Morumbi, v. 1, nº 1, p. 89-117, 2002.

SCHWARZ, Roberto. Um mestre na periferia do capitalismo. In de Assis. São Paulo: Companhia das Letras, 2006, p. 236-278.

Por um novo Machado

SOUZA, Antônio Cândido de Mello e. A formação da literatura brasileira. São Paulo: Itatitaia, 1959.

SOUZA, Gilda de Mello e. 0 espírito das roupas: a moda no século XIX. São Paulo: Companhia das Letras, 2009.

WOOLF, Virginia. Orlando. Rio de Janeiro: Nova Fronteira, 2003.

0 vestido novo. In: Contos completos. São Paulo: Cosac Naify, 2005.

Um teto todo seu. Rio de Janeiro: Nova Fronteira, 2005. 